\title{
Dendroaxonal Transcytosis of Transferrin in Cultured Hippocampal and Sympathetic Neurons
}

\author{
Agnès Hémar, ${ }^{1,4}$ Jean-Christophe Olivo, ${ }^{2}$ Edward Williamson, ${ }^{1}$ Rainer Saffrich, ${ }^{3}$ and Carlos G. Dotti ${ }^{1}$ \\ ${ }^{1}$ Cell Biology Programme, ${ }^{2}$ Cell Biophysics Programme, and ${ }^{3}$ Biochemical Instrumentation Programme, European \\ Molecular Biology Laboratory, 69117 Heidelberg, Germany, and 4Unité de Biologie des Interactions Cellulaires, Unité de \\ Recherche Associée Centre National de la Recherche Scientifique 1960, Institut Pasteur, 75724 Paris, France
}

Previous studies using overexpressed polymeric immunoglobulin receptor in cultured neurons have suggested that these cells may use a dendroaxonal transcytotic pathway (lkonen et al., 1993; de Hoop et al., 1995). By using a combination of semiquantitative light microscopy, video microscopy, and a biochemical assay, we show that this pathway is used by the endogenous ligand transferrin (Tf) and its receptor. Labeled Tf added to fully mature hippocampal neurons changes the intracellular distribution of its receptor from preferentially dendritic shortly after addition to dendritic and axonal at longer times. Incubation of living neurons with (caged)FITC-Tf followed by uncaging in the dendrites results in the later appearance of fluorescence in the axon of the same cell. In "chambered" sympathetic neurons in culture, ${ }^{125} \mathrm{I}-\mathrm{Tf}$ or iron as ${ }^{55} \mathrm{Fe}-\mathrm{Tf}$ added to the cell body/dendrite chamber is recovered in the axonal chamber, showing that internalized ligand from the cell bodydendrite area is released at the axonal end. Finally, we show that excitatory neurotransmitters increase Tf receptor transcytosis, whereas inhibitory neurotransmitters reduce it. The dendritic uptake, transcytotic transport, and axonal release of physiologically active Tf demonstrated here could be envisioned for other trophic factors and therefore have important consequences for neuronal anterograde target maturation. Moreover, the changes in transcytosis after neurotransmitter addition may be important in the cellular responses that follow electrical activation.

Key words: transferrin; receptor; L-glutamate; hippocampal neurons; sympathetic neurons; transcytosis
In polarized cells the movement of molecules endocytosed at one plasma membrane domain followed by transport to the opposite is called transcytosis (for review, see Mostov, 1991; Nelson, 1992; Mostov and Cardone, 1995). The best-characterized transcytotic molecule is the polymeric immunoglobulin receptor (pIgR). Newly synthesized receptors first are targeted to the basolateral surface of epithelial cells, where after binding to the ligand they undergo transport across cells to the apical surface where, after cleavage, ligand and receptor are released. At least three sorting events take place in this event. The first is sorting in the Golgi apparatus for basolateral delivery. The second is sorting in the plasma membrane into clathrin-coated pits for endocytosis and transport to basolateral early endosomes. The third is in the basolateral endosomes, where the receptor must be sorted into transcytotic vesicles and thus avoids transport to the degradative compartment or the recycling compartment or both. In epithelial and endothelial cells, transcytosis has been shown to occur for molecules such as immunoglobulins (Hunziker and Mellman,

Received April 11, 1997; revised Sept. 15, 1997; accepted Sept. 18, 1997.

We thank Liane Meyn for excellent technical assistance, Drs. Sigrid Reinsch, Alice Dautry-Varsat, Kai Simons, Marino Zerial, and Robert G. Parton for discussions and critical reading of this manuscript, Dr. Alice Dautry-Varsat for the gift of TRITC-Tf used in preliminary experiments, and Dr. Carol Murphy for advice and discussions. We especially thank Dr. Wolfgang Jarolimek (Department of Physiology, Heidelberg University) for advice on the use of the neurotransmitters. A.H. is a recipient of an EMBO fellowship. E.W. is a recipient of a United States Public Health Service National Research Service Award. C.G.D is partially supported by a Sonderforschungbereigh (SFB 317) grant.

Correspondence should be addressed to Carlos G. Dotti, European Molecular Biology Laboratory, Meyerhofstrasse 1, 69117 Heidelberg, Germany.

Dr. Hémar's present address: Unité Mixte de Recherche Centre National de la Recherche Scientifique 5541, Université Victor Segalen Bordeaux 2, 33076 Bordeaux Cedex, France.

Copyright (C) 1997 Society for Neuroscience $0270-6474 / 97 / 179026-09 \$ 05.00 / 0$
1989; Sooranna and Contractor, 1991; Neutra et al., 1988), nerve growth factor (NGF) (Siminoski et al., 1986), epidermal growth factor (EGF) (Maratos-Flier et al., 1987; Brändli et al., 1991), insulin (King and Johnson, 1985), human gonadotropin hormone (hGC), (Ghinea et al., 1994), and transporter molecules such as LDL (Hashida et al., 1986) or transferrin (Tf) (Soda and Tavassoli, 1984; Friden et al., 1991; Cerneus et al., 1993). Neuronal cells, like epithelia, are highly polarized (for review, see Rodriguez-Boulan and Powell, 1992; Craig and Banker, 1994). Although neuronal transcellular transfer has been demonstrated for viruses, toxins, immunoglobulins, trophic factors, and fluid phase molecules (Dumas et al., 1979; Pickard and Silverman, 1981; Evinger and Erichsen, 1986; LaVail and Margolis, 1987; Kuypers and Ugolini, 1990; Ikonen et al., 1993; de Hoop et al., 1995; von Bartheld et al., 1996), the existence of a neuronal transcytotic pathway similar to that of epithelial cells (see above) is suggested primarily from studies with wheat germ agglutinin (WGA) (LaVail and Margolis, 1987) and the pIgR (Ikonen et al., 1993; de Hoop et al., 1995). WGA injected into the aqueous chamber of the eye is taken up by endocytosis from the dendrites of the retinal ganglion cells, and after crossing the cells without a major concentration in the Golgi apparatus, it concentrates later in vesicular structures in the axons of the optic nerve. pIgR, a transcytotic molecule of epithelia, when expressed in cultured hippocampal neurons is first delivered from the cell body to the dendritic surface, where after binding to its ligand is transported to dendritic early endosomes and later to vesicular structures in the axons.

In this work we have investigated the intracellular trafficking of Tf receptor (TfR) and its ligand Tf. Tf is the major irontransporting protein in the vertebrate body. Iron $\left(\mathrm{Fe}^{3+}\right)$ is a 
universal cofactor for mitochondrial energy regeneration, and it supports the growth and differentiation of all cell types. In the CNS, iron is a key component of systems responsible for myelination and the synthesis of several neurotransmitters (Beard et al., 1993). Although an essential nutrient, iron is also a potent toxin because it is a powerful oxidant and must therefore be stringently regulated. Dysfunction in iron metabolism has been involved in brain disorders such as Parkinson's and Alzheimer's diseases (for review, see Faucheux et al., 1995; Loeffler et al., 1995). Iron reaches the brain using a TfR-mediated process that is not yet fully understood. It is taken up by brain $\mathrm{Tf}$ and transported into TfR-expressing cells. In the cytosol, iron is complexed with the iron-binding protein ferritin. Major sites of accumulation of iron in the brain are oligodendrocytes, located mainly in the basal ganglia. Studies comparing the differential localization of iron and TfRs in the brain led to the hypothesis that iron might be vectorially transported via neurons expressing high level of TfRs toward the iron storage zones (Hill et al., 1985). This hypothesis is supported by data showing that injected radioactive iron is found first in the receptor-rich regions and some weeks later in the storage zones (Morris et al., 1992). Axonal release of $\mathrm{Tf}$ has been observed in the peripheral nervous system, although neurons do not synthesize any Tf (Markelonis et al., 1985; Kiffmeyer et al., 1991). Although indicative of brain transcytosis of $\mathrm{Tf}$, neither of these observations formally examine the question of neuronal transcytosis or the cell biology of this phenomenon.

Using three complementary approaches, quantitative immunofluorescence light microscopy and video microscopy of hippocampal neurons in culture and a biochemical assay of Tf/iron uptake and release in sympathetic neurons grown in "Campenot" chambers (Campenot, 1992), we show that Tf and its receptor undergo dendroaxonal transcytosis. Moreover, we show that transcytosis of the TfR is modulated by exogenous $\mathrm{Tf}$ and neurotransmitters.

\section{MATERIALS AND METHODS}

\section{Cells}

Rat hippocampal neurons. Hippocampal cells were prepared from 18-dold rat embryos according to the method of Goslin and Banker (1991). Briefly, the hippocampi are dissociated by trypsin and mechanical treatments. Cells are plated onto poly-L-lysine-treated glass coverslips. After allowing attachment for 4-12 hr in medium (N2 medium) containing $10 \%$ horse serum, the coverslips are transferred to dishes containing a monolayer of glial cell in a serum-free medium (N2 medium). Proliferation of non-neuronal cells was prevented by adding $5 \mu \mathrm{M}$ cytosine arabinoside (ARA-C) (Calbiochem, La Jolla, CA). All experiments were performed in cells kept $14-21 \mathrm{~d}$ in culture.

Sympathetic explants and compartmentalized culture. Superior cervical ganglia were dissected from 19- to 20-d-old rat embryos in L15 medium (Life Technologies), and the capsule was dissected and directly seeded onto collagen-coated tissue culture dishes (explants) or dissociated by enzymatic and mechanical treatment as described (Higgins et al., 1991). Dissociated cells (approximately two ganglia) were plated in the central chamber of three-compartment Campenot chambers (camp2, Tyler Research Instrument, Edmonton, Alberta). These chambers have been sealed via prewetted silicone grease on collagen-coated (Collaborative Research, Bedford, MA; Becton Dickinson, Heidelberg, Germany) dishes exactly as described (Campenot, 1992). The plating medium is F12/DMEM medium (Life Technologies, Gaithersburg, MD) supplemented with N2 (Bottenstein and Sato, 1979), 0.1\% egg albumin, $1 \mathrm{~g} / 1$ $\mathrm{NaHCO}_{3}, 2 \mathrm{~mm}$ glutamine, $0.2 \mu \mathrm{g} / \mathrm{ml}$ triiodothyrosine, $10 \mu \mathrm{M}$ each of fluorodeoxyuridine and uridine, $1 \%$ horse serum, and $100 \mathrm{ng} / \mathrm{ml} \mathrm{NGF}$ (Alamone Labs, Jerusalem). Culture medium, i.e., plating medium without horse serum, and $25 \mathrm{ng} / \mathrm{ml} \mathrm{NGF}$ were added the following day. The cells were fed three times per week, and $5 \mu \mathrm{M}$ ARA-C was added once in the culture to eliminate non-neuronal cells. After 1 week, axons begin to appear in the lateral chambers.

\section{Tfs and antibodies}

Human holo-Tf (Sigma, St. Louis, MO) was coupled to rhodamine (lissamine rhodamine B sulfonyl chloride, Molecular Probes, Eugene, OR) and CMNB-caged fluorescein SE (5-(((() succinimidyl) oxy)carbonyl)butanoyl)amino)fluorescein-bis-5-carboxymethoxy-2-nitrobenzyl)ether; Molecular Probes) according to the manufacturer's recommendation, with the following modifications: (1) the fluorochrome was added in five steps at 5 min intervals, and (2) the reaction was stopped after $1 \mathrm{hr}$ in 1 $\mathrm{mm}$ glycine, $\mathrm{pH}$ 8.5. Coupled and free fluorochrome were separated on a PD10 column (Pharmacia, Piscataway, NJ) and eluted in a Na-HEPES, $\mathrm{pH} 7.2,0.15 \mathrm{~m} \mathrm{NaCl}$ buffer. Human apo-Tf (Sigma) was coupled to ${ }^{55} \mathrm{Fe}$ as described (Sterverding et al., 1995).

MAP2 rabbit polyclonal was provided by Javier Diez-Guerra, Centro Biología Molecular, Madrid Spain, and was used at 1:1000 dilution; monoclonal anti-(rat) TfR clone OX26 (PharMingen, San Diego, CA) was used at $1 / 00$.

\section{Endocytosis experiments}

For the internalization of labeled $\mathrm{Tf}, \mathrm{Rh}$ or (caged)FITC-cells were incubated for $2 \mathrm{hr}$ at $37^{\circ} \mathrm{C}$ in culture N2 medium (Goslin and Banker, 1991), with or without $\mathrm{Tf}$, and then incubated for different times in N2 medium (without TF) containing $300 \mathrm{~nm}$ of either Rh or (caged)FITClabeled human Tf. The cells were then fixed and analyzed by immunofluorescence microscopy or mounted for fluorescence video microscopy (see below).

\section{Activation of $G A B A$ and glutamate synapses}

DL-glutamic acid (glutamate) and GABA (Sigma) were added at concentrations of $5 \mu \mathrm{M}$ and $10 \mu \mathrm{M}$, respectively. Hippocampal neurons were incubated for $4 \mathrm{hr}$ in the presence of Fe-Tf and then for $2 \mathrm{hr}$ in Tf-free medium (starvation) or in Fe-Tf containing medium in the presence of glutamate or GABA, fixed, and stained using an anti-TfR antibody (see below).

\section{Immunofluorescence}

After Rh-Tf internalization, cells on coverslips were fixed in $4 \%$ paraformaldehyde in PBS for $30 \mathrm{~min}$ at room temperature followed by quenching of aldehyde groups with $50 \mathrm{~mm} \mathrm{NH}_{4} \mathrm{Cl}$ in PBS for $10 \mathrm{~min}$, mounted, and analyzed by fluorescence microscopy. For the detection of the TfR under the different experimental conditions (see Results), cells were fixed as above and then permeabilized in PBS $/ 5 \%$ blocking solution $/ 0.05 \%$ saponine for $10 \mathrm{~min}$ at $37^{\circ} \mathrm{C}$, incubated for $1 \mathrm{hr}$ with the anti MAP2 and anti-TfR antibodies, washed three times and incubated for 1 hr with fluorochrome-coupled secondary antibodies, washed three times with permeabilizing buffer and once in PBS and once in water, and finally mounted in Dabco/Mowiol as described in Hémar et al. (1995).

\section{Image analysis}

A semiautomatic program was developed to detect, count, and localize vesicles. It runs on a Series 151 digital image processor (Imaging Technology, Bedford, MA) hosted by a SPARCstation 20 (SUN, Mountain View, CA). The program recognizes vesicles by applying a two-step strategy method (Olivo, 1992): (1) all possible vesicle candidates are detected by local maxima filtering; and (2) a measuring mask is applied at each such position, and real vesicles are selected according to geometrical criteria, such as size and spacing, and statistical criteria, such as intensity, average, and SD values against local background. Region masks defining dendrite and axonal processes are defined by thresholding the fluorescence images and retaining pixels with values above an interactively selected threshold or by interactively drawing an overlay over the phase contrast, and for each image the cross-sectional areas of axons and dendrites are measured $\left(s_{\mathrm{ax}}\right.$ and $\left.s_{\mathrm{dd}}\right)$. Vesicles are finally counted and attributed to either the axonal $\left(v_{\mathrm{ax}}\right)$ or the dendritic $\left(v_{\mathrm{dd}}\right)$ compartment by applying a logical AND operator between the vesicle and masks images. The results are presented as the mean \pm SEM of the percentage of the number of axonal vesicles relative to the total number of vesicles, $\left(v_{\mathrm{ax}} / s_{\mathrm{ax}}\right) /\left(v_{\mathrm{ax}} / s_{\mathrm{ax}}+v_{\mathrm{dd}} / s_{\mathrm{dd}}\right) \times 100$. To determine statistical significances, the total number of Tf- or TfR-labeled vesicles in axons and dendrites (see Results for the number of cells analyzed for each experiment) under the different experimental conditions was subjected to Student's $t$ test analysis as described in Press et al. (1992).

\section{Video microscopy}

Hippocampal neurons grown at low density were deprived of $\mathrm{Tf}$ (starved), incubated for $20 \mathrm{~min}$ with (caged)FITC-Tf, rinsed, mounted 
in a homemade video chamber containing normal culture medium (with Tf) without phenol red, and observed with a $63 \times$ PlanNeofluar lens in a Zeiss inverted microscope (Axiovert). Cells grown in relative isolation with a large dendritic tree and an identifiable axon were chosen by phase contrast microscopy and then illuminated for $1 \mathrm{sec}$ with the FITC excitation wavelength. This always resulted in lack of emission. To uncage the (caged)FITC-Tf, a small region of the dendrites was illuminated with the UV filter with the field aperture closed to its minimum (this resulted in the excitation of an area of $\sim 5 \mu \mathrm{m}$ in diameter). After UV excitation, uncaging was confirmed by excitation with the FITC wavelength. The axon of the cell in which uncaging was performed was then visualized in the FITC channel with a $1 \mathrm{sec}$ exposure every $5 \mathrm{~min}$. All images were captured with an SIT camera (Hamamatsu, Photonics Deutschland) and processed in a Power Macintosh (9100) computer equipped with a Scion LG3 image grabber (Scion Co.). Images were analyzed using National Institutes of Health image processing software.

\section{Electron microscopy}

Electron microscopy was used to examine $\mathrm{Tf}$-positive structures in the cells. Neurons, grown on coverslips, were incubated with Tf-HRP for $25 \mathrm{~min}$ in serum-free media at $37^{\circ} \mathrm{C}$, washed in serum-free media, and fixed using $2.5 \%$ glutaraldehyde in $50 \mathrm{~mm}$ sodium cacodylate buffer, $\mathrm{pH}$ 7.35 , for $30 \mathrm{~min}$ at room temperature. After they were fixed, neurons were washed with cacodylate buffer and reacted with diaminobenzidine to visualize the Tf-HRP (Parton et al., 1992). Neurons were subsequently post-fixed in $2 \% \mathrm{OsO}_{4}$ for $1 \mathrm{hr}$ at $4{ }^{\circ} \mathrm{C}$ and washed with $\mathrm{dH}_{2} \mathrm{O}$. Cells were selected using an inverted microscope and marked on coverslips for en face sectioning subsequent to electron microscopy processing. Cells on coverslips were stained with $0.5 \%$ uranyl acetate and dehydrated through a graded series of ethanol. Epon was infiltrated into neurons for several hours, and the plastic was polymerized overnight at $60^{\circ} \mathrm{C}$. Marked cells were cut out and glued onto blank plastic stubs so that neurons could be cut parallel to their growing surface. Sections with a gold interference color were cut, picked up on formvar-coated grids, and viewed in a Zeiss EM10 electron microscope operated at $60 \mathrm{kV}$, without section staining.

\section{Immunoprecipitation of $T f R$}

Newly synthesized proteins in sympathetic neurons grown in explants were labeled with $200 \mu \mathrm{Ci} / \mathrm{ml}$ of ${ }^{35} \mathrm{~S}$-methionine for $6 \mathrm{hr}$ in medium containing 1:10 cold methionine (metabolic pulse). At the end of the pulse, cells were chased for $16 \mathrm{hr}$ in medium deprived of or containing $100 \mathrm{~nm}$ Tf. Then, cell body and axonal masses were separated with a razor blade, the material was lysed, large aggregates were discarded after centrifugation, and aliquots of supernatant were subjected to trichloroacetic precipitation and used for scintillation counting. Equal amounts of radioactivity were then subjected to immunoprecipitation as described by De Strooper et al. (1995) using antibody against TfR OX-26. Immunoprecipitates were subjected to SDS-PAGE, and the gel was dried and exposed to $x$-ray film. Autoradiograms were scanned and radiaoctivity was quantitated using National Institutes of Health Image software.

\section{Transcytosis assay in chambered sympathetic neurons}

${ }^{3} \mathrm{H}$-inulin (TR A 324, Amersham, Arlington Heights, IL) (0.5 $\mu \mathrm{ci} / \mathrm{ml}, 1-5$ $\mathrm{Ci} / \mathrm{ml})$ 1:1000 in medium without $\mathrm{Tf}$ was first added in the central chamber, and cells were incubated for $2 \mathrm{hr}$ at $37^{\circ} \mathrm{C}$. Then lateral and central chambers milieu were collected and washed, and radioactivity was counted. In nonleaking cultures (as assayed by the lack of ${ }^{3} \mathrm{H}$-inulin in the lateral chambers), $300 \mathrm{~nm}{ }^{125} \mathrm{I}$-Tf (labeled as described in Fracker and Specks, 1978) was diluted in medium without $\mathrm{Tf}$ and added to the central chamber for $1 \mathrm{hr}$ at $37^{\circ} \mathrm{C}$. The central and lateral chambers were then washed, and the medium in the lateral chambers was replaced by N2 medium without $\mathrm{Tf}$ and with $5 \mathrm{~mm}$ nitrilotriacetic acid to prevent the re-endocytosis of released $\mathrm{Tf}$. The radioactive $\mathrm{Tf}$ endocytosed in the first hour was allowed to recycle or transcytose for $2 \mathrm{hr}$ at $37^{\circ} \mathrm{C}$, the medium was collected, and radioactivity was counted. After washing, $96 \mathrm{~nm}{ }^{55} \mathrm{Fe}$ was added to the central chambers of the same cultures, and the same procedure was followed.

\section{RESULTS}

\section{Rhodamine-Tf is redistributed from dendritic to axonal intracellular compartments in rat hippocampal neurons in culture}

We first analyzed the intracellular distribution of Tf after different times of internalization. Hippocampal neurons were preincubated for $2 \mathrm{hr}$ in $\mathrm{Tf}$-free medium (Tf starvation), and then rhodamine-labeled $\mathrm{Tf}(\mathrm{Rh}-\mathrm{Tf})$ was added for 20 or $90 \mathrm{~min}$ at $37^{\circ} \mathrm{C}$. The cells were fixed, and the distribution of the labeled ligand to the axonal and dendritic territories was determined and quantified. To define axons and dendrites, the dendritic territory was labeled with the specific marker MAP2 (Caceres et al., 1984). Axons were then defined by phase contrast microscopy and by the lack of MAP2 staining. The results of these experiments are shown in Figure 1. After a short time of endocytosis, Rh-Tf labeling appeared as small dots present mainly in the dendrites (Fig. 1A, $a-c$ ). Axonal labeling was evident after $90 \mathrm{~min}$ of endocytosis (Fig. $1 A, d-f$ ). To determine the location of the ligand to either axons or dendrites, we used a semiautomatic computer software (described in Materials and Methods) that permitted us to compare the relative amounts of fluorescent vesicles in axons and dendrites from experiment to experiment. By using this program, region masks of dendrite and axonal processes are first defined. Because some axons may run along dendrites, only the axons running in isolation were counted. Moreover, to avoid overestimation of dendritic vesicles caused by vesicles present in axons running parallel to dendrites, vesicles located on the edge of the dendritic mask were not taken into account. Then bright spots representing vesicles were counted and attributed to either the axonal or dendritic domains, and their number was normalized per surface unit (Fig. 1B). By this means, diff use surface fluorescence is not taken into account. The use of this semiquantitative method revealed a $46 \%$ increase in the percentage of axonal Tf-labeled vesicles after $90 \mathrm{~min}$ of incubation compared with that after $20 \mathrm{~min}$. In absolute values, $18.6 \pm 2.8 \%$ of $\mathrm{Tf}$-labeled vesicles were found in axons after 20 min of internalization, and $27.2 \pm 3.2 \%$ were found after 90 min (Fig. 1C).

Although not dramatic, the change in distribution of $\mathrm{Tf}$ at different times of internalization, from preferentially dendritic to dendritic and axonal, suggests transcytosis. However, the use of this method does not permit us to conclude whether the axonal $\mathrm{Tf}$ after $90 \mathrm{~min}$ is originated in the dendritic/cell body region, transcytosis, or attributable to a different kinetics of axonal internalization.

\section{Transcytosis of (caged)FITC-Tf in living hippocampal neurons}

To examine more directly the transcytotic movement of internalized Tf, we then analyzed the distribution of (caged)FITC-Tf in living hippocampal neurons. Caged compounds are not fluorescent on excitation at $490 \mathrm{~nm}$ unless first uncaged by excitation at a wavelength under $360 \mathrm{~nm}$ (Mitchinson, 1989). Hippocampal neurons were incubated for 30 min with (caged)FITC-labeled Tf. After excess ligand washing, the cells were mounted for video microscopy analysis in normal culture medium (see Materials and Methods). Under phase contrast observation, a cell was chosen and then illuminated first at the excitation wavelength of FITC. As shown in Figure $2 B$, no fluorescein labeling was observed in the entire neuron. Illumination at $360 \mathrm{~nm}$ (Hoechst filter) of two small dendritic areas $(\sim 5 \mu \mathrm{m}$ in diameter) resulted in the appear- 
A
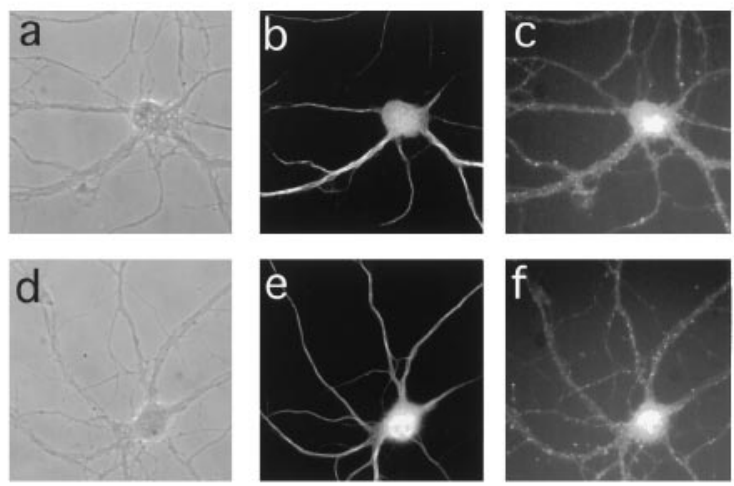

Axonal mask

B

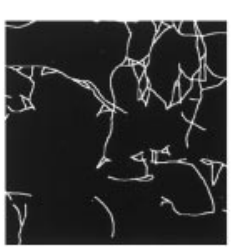

13483 pixels dendritic mask

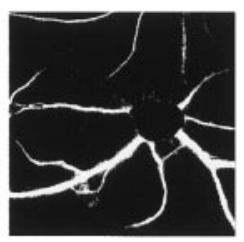

24181 pixels
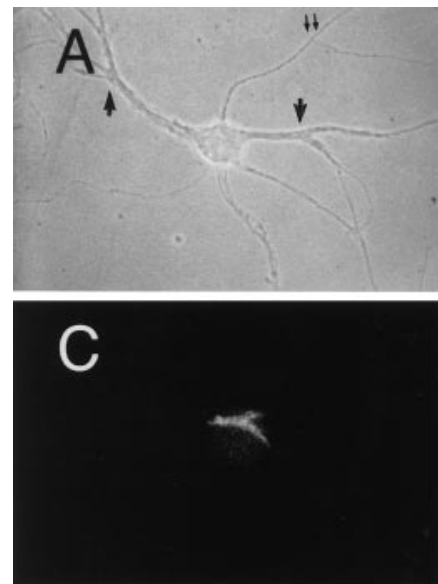

vesicles

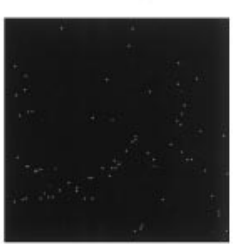

7 axonal vesicles 47 dendritic vesicles

C

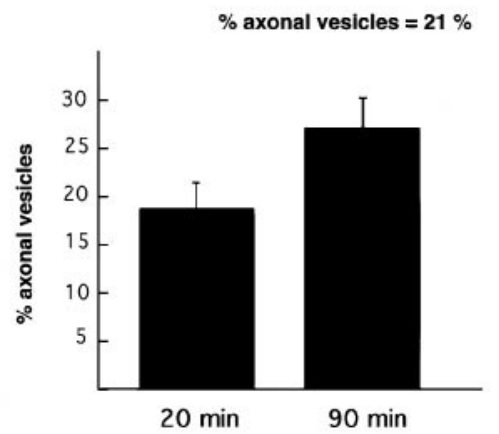

Figure 1. Dendritic and axonal distribution of internalized Tf. A, Hippocampal neurons were incubated for $2 \mathrm{hr}$ in medium without $\mathrm{Tf}$ followed by incubation in $300 \mathrm{~nm} \mathrm{Rh-Tf}$ for $20 \mathrm{~min}(a-c)$ and $90 \mathrm{~min}(d-f) . a, d$, Phase contrast; $b, e$, MAP2 labeling (dendritic marker); $c$, internalized Tf. After 20 min of internalization (c) Tf positive structures are preferentially dendritic (compare the distribution of dots in $c$ with that of the MAP2-positive processes in $b$ ). After $90 \mathrm{~min}$ of internalization $(f)$, numerous dots are present in processes (small arrows in $f$ ) negative for MAP2 (e). B, Example (based on the cell shown in $A, a-c$ ) of how the computer program identifies axons and dendrites and determines the distribution of Tf-positive (rhodamine) dots. The computer recognizes dendrites on the basis of MAP2 labeling (middle panel) and axons by phase contrast (left panel) and lack of MAP2 labeling, and then allocates and counts the $\mathrm{Tf}$ dots. $C$, With longer incubation times there is an increase in Tf-positive structures in axons.

ance of fluorescent dots exclusively in the excited areas (Fig. $2 C, D)$ corresponding to the internalized Tf. The axon of this cell, identified by conventional morphological criteria (thin and of uniform area), did not show any fluorescence immediately after uncaging of FITC in the dendrites (Fig. 2E). However, some labeled vesicles were evident 45 min later (Fig. 2F). Labeled structures were also found in the cell body (not shown). Because Tf was made fluorescent only in the dendrites, this result shows that ligand internalized from this surface can move to the axons, thus proving the existence of dendroaxonal transcytotic movement. Whether Tf transcytosed bound to its receptor was analyzed next.
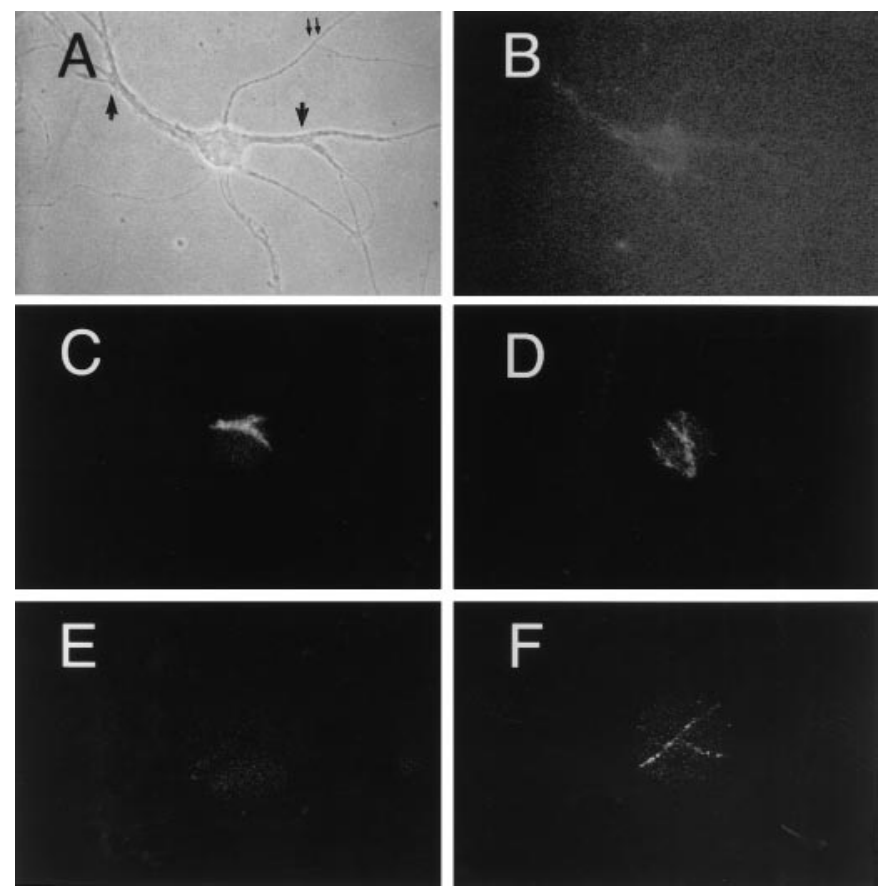

Figure 2. Dendritically uncaged FITC-Tf is later present in axons. Cells were incubated with $300 \mathrm{~nm}$ (caged)FITC-Tf for $30 \mathrm{~min}$ and then analyzed by video microscopy. $A$, Phase-contrast image of hippocampal neuron grown at low density. $B$, Excitation with FITC wavelength reveals only autofluorescence but no Tf-labeled structures [compare with the dots seen in fluorochrome (uncaged)-conjugated images of Figure 1]. The high background is caused by the increase in the camera sensitivity to permit the visualization of the cell. $C, D$, With the mercury light diaphragm closed to its maximum, two dendritic areas are uncaged by a $1 \mathrm{sec}$ illumination with UV wavelength. Only the dendrites are exposed. The rest of the cell is invisible. Switching back to FITC wavelength reveals the presence of Tf-positive dots in the excited dendrites (arrows in $A$ ). E, Excitation of the axon of this cell (double arrows in $A$ ) with FITC wavelength immediately after dendritic UV uncaging reveals no emission. $F$, At 45 min after dendritic uncaging, several FITC-positive dots in the axon are evident.

\section{Tf receptor is redistributed from the dendrites to the axons in the presence of ligand}

The intracellular pathway of $\mathrm{Tf}$ and its receptor in nonpolarized cells is well known. Diferric-Tf (holo-Tf) binds to its receptor at neutral $\mathrm{pH}$ and is endocytosed. At the acidic $\mathrm{pH}$ of the endosomes, iron dissociates from $\mathrm{Tf}$ (apo-Tf), which still bound to the receptor is recycled back to the cell surface where it dissociates and becomes free for another round of binding and internalization (Dautry-Varsat et al., 1983; Klausner et al., 1983). Thus, inside the cell $\mathrm{Tf}$ and receptor remain together. Because in Tf-starved hippocampal neurons $\mathrm{Tf}$ is preferentially internalized from dendrites after short times of endocytosis (Fig. 1 $A, a-c$ ) but then appears in the axons at longer times (Fig. $1 A, d-f$ ), a similar change in distribution would be expected for the TfR .

Hippocampal neurons were incubated for $2 \mathrm{hr}$ in Tf-free/ serum-free medium (starvation, see Materials and Methods), fixed, and stained using an anti-TfR antibody. Under this experimental condition the TfR appeared preferentially dendritic (Fig. $3 A, a-c)$. By comparing identical axonal and dendritic surface areas, our quantitative analysis revealed that $86.3 \%$ of the TfRcontaining vesicles are dendritic (Fig. 3B, after starvation), thus confirming previous results (Cameron et al., 1991; Parton et al., 1992). However, in cells incubated with Fe-Tf, axonal labeling 
A
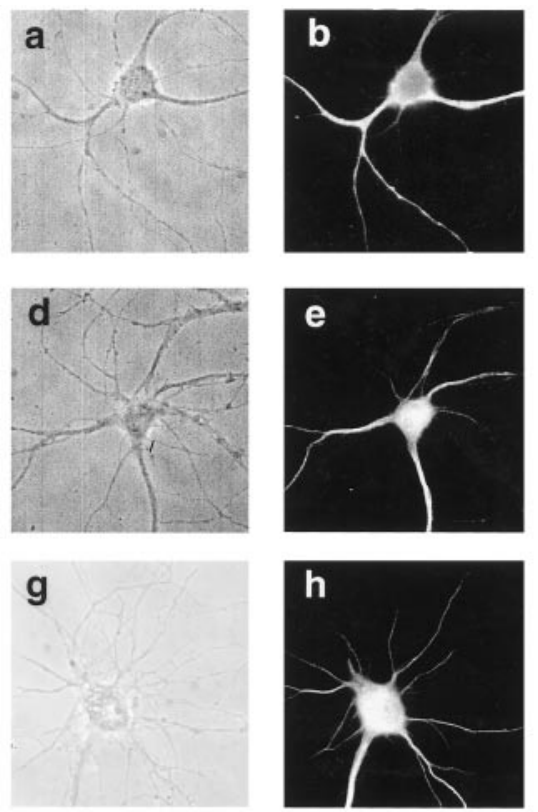

$\mathbf{B}$

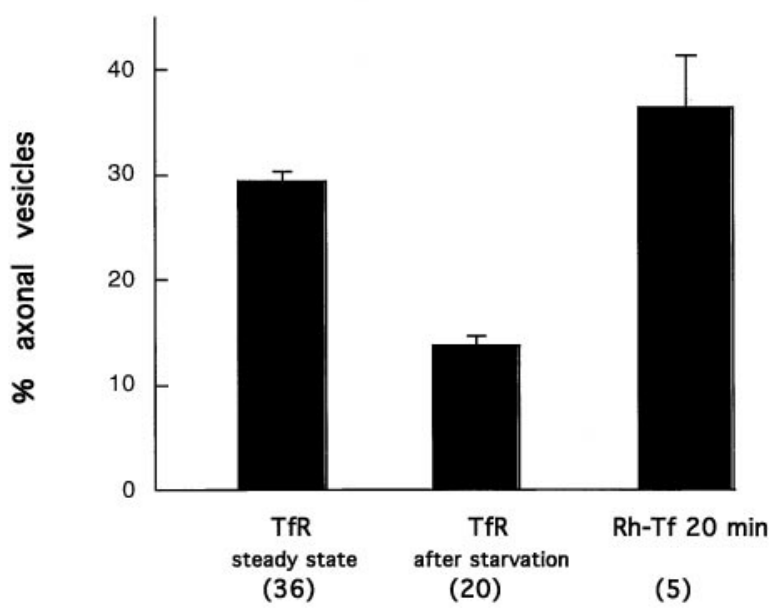

Figure 3. The distribution of the receptor changes after ligand addition. $A$, Hippocampal neurons were incubated for $2 \mathrm{hr}$ in medium without $\mathrm{Tf}$ $(a-c)$ or with $300 \mathrm{~nm}$ holo-Tf $(d-f)$. The cells were then fixed, permeabilized, and double-labeled with an antibody against the $\operatorname{TfR}(c, f)$ and the dendritic marker MAP2 $(b, e)$. Without Tf in the medium the receptor is preferentially dendritic (compare the distribution of the TfR dots in $c$ with that of MAP2-positive dendrites in $b$ ). After ligand addition, several dots are evident in axons, as evidenced by their lack of MAP2 staining (e). $g-i$, Nonstarved cells (as in $d-f$ ) incubated for 20 min with $\mathrm{Rh}-\mathrm{Tf}(i)$, fixed, and analyzed by fluorescence microscopy. Even after $20 \mathrm{~min}$ of internalization, axonal positive structures are seen. $\mathrm{Rh}-\mathrm{Tf}$ dots are abundant in both axons and dendrites (compare with the pattern of MAP2 labeling of this cell in $h$ ). $B$, In the presence of Tf in the medium (TfR steady state) the number of TfR-positive structures in axons increases more than twofold with respect to cells starved for $2 \mathrm{hr}$ (absolute values and significance are given in text). The number of cells analyzed is in parentheses.

increased (Fig. 3A, $d-f$ ). Quantitative analysis shows that in the presence of $\mathrm{Tf}$ in the medium, the percentage of axonal TfRcontaining vesicles increased 2.1 -fold $(29.4 \%$ at steady state vs $13.7 \%$ after starvation; $p<0.001$ ) (Fig. $3 B$ ). To prove that indeed the receptor present in axons had reached the axonal surface, cells maintained in Tf-containing medium were incubated for 20 min with $\mathrm{Rh}-\mathrm{Tf}$, and the percentage of internalized $\mathrm{Tf}$ in axons

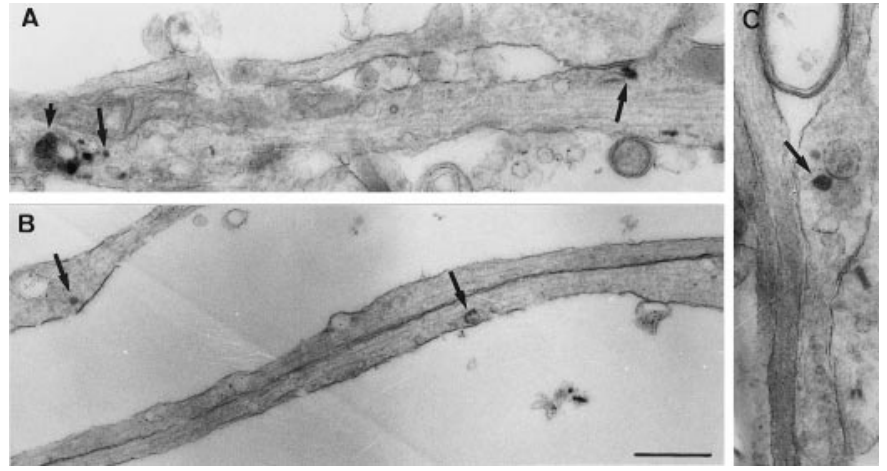

Figure 4. Tf in axons is found in small vesicles. Hippocampal neurons were incubated for $20 \mathrm{~min}$ with Tf-HRP and processed for electron microscopy analysis. $A$, In semithick sections, dendritic (dendrites were identified by the presence of ribosomes and contacting presynaptic terminals) Tf-HRP-positive structures appear as large, endosomal-like structures (short arrow) and also as small vesicles (large arrows). B, C, $\mathrm{Tf}-\mathrm{HRP}$ in axons. Tf-HRP is present in vesicles in both axonal shafts $(B)$ and presynaptic varicosities $(C)$. Scale bar, $1 \mu \mathrm{m}$.

and dendrites was determined. In these cells, $36.6 \%$ of fluorescent dots were in axons (Fig. $3 A, g-h$; quantitation in Fig. $3 B$ ). This amount is significantly different $(p<0.05)$ from the $18.6 \%$ observed after $2 \mathrm{hr}$ starvation followed by $20 \mathrm{~min}$ internalization (see first part of Results). This result shows that the low axonal labeling observed after 20 min endocytosis of Rh-Tf in starved cells as compared with 90 min endocytosis was not caused by a kinetic difference of $\mathrm{Tf}$ endocytosis in axons and dendrites.

Altogether this last series of experiments suggests that both $\mathrm{Tf}$ and TfR follow a similar transcytotic route from dendrites to axons and that this transcytosis of $\mathrm{TfR}$ is stimulated by the binding of Tf. It is unlikely that the significant change in TfR distribution is caused by an increase in axonal mass, because we are using fully developed, synaptically active neurons that have little growth capacity and, even if they do grow, the time of incubation $(2 \mathrm{hr})$ is too short to account for significant process elongation.

\section{Transcytosed Tf is present in vesicles in the axons}

To analyze the morphological appearance of Tf-containing structures in both axons and dendrites, we performed electron microscopy of cells maintained in Tf-containing medium incubated for 20 min with Tf coupled to HRP. HRP-positive structures were indeed found in axons and dendrites (Fig. 4). Vesicles and tubules filled with reaction product were seen in the dendrites. In the axons, labeled vesicles were observed along both axonal shafts (Fig. 4B) and varicosities (Fig. 4C). Although this experiment does not conclusively demonstrate that the axonal Tf-containing vesicles are indeed transcytotic, this could be inferred from the fact that the axonal $\mathrm{Tf}$ is in small vesicular structures and not in the large multivesicular body-like vesicles, the classic carriers of retrogradely transported material (Parton et al., 1992).

\section{Use of Campenot chambers reveals that Tf and iron are taken up from the cell body/dendrites and released from the axons}

We used dissociated sympathetic neurons grown in Campenot chambers to biochemically determine dendroaxonal transcytosis of Tf. This culture system consists of a central and two lateral chambers. In this compartmentalized culture, axons originating from neurons plated in the central chamber grow across a silicone grease layer barrier and enter a separate fluid environment within 
A

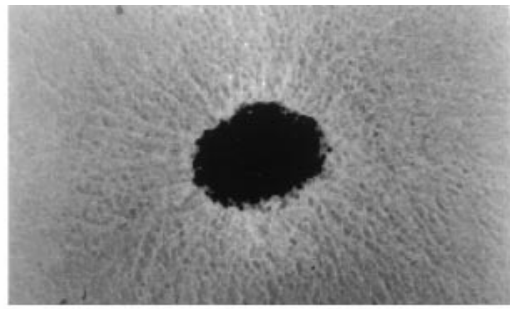

B

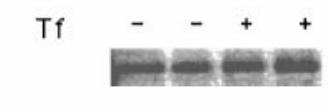

cb a cb a

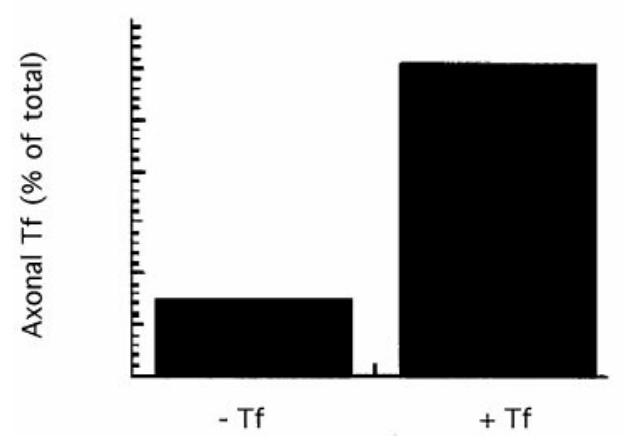

Figure 5. A, Explants of embryonic rat sympathetic ganglia. The central mass contains cell bodies and short dendrites, and the peripheral halo contains only axons. Both territories can be mechanically separated for biochemical analysis. $B$, Immunoprecipitation of newly synthesized proteins with a TfR antibody reveals an increase in the amount of receptor in the axon on addition of $\mathrm{Tf}$ to the chase medium (see Materials and Methods).

the lateral compartment (Campenot, 1992). Before using the compartmentalized system we determined whether in sympathetic neurons $\mathrm{TfR}$ changed distribution from preferentially cell body/dendritic to axonal in the presence of exogenous Tf (Figs. 1, 3). For this, we used sympathetic explants in which the central cell body mass can be easily separated from the peripheral halo of axons (Fig. $5 A$ ). ${ }^{35}$ S-methionine labeling of newly synthesized proteins followed by a chase in the presence or absence of exogenous $\mathrm{Tf}$ and immunoprecipitation with an anti-TfR antibody revealed a significant increase in the amount of $\mathrm{TfR}$ in the axonal mass on addition of exogenous $\mathrm{Tf}$ (Fig. $5 B$ ). This result implies that $\mathrm{Tf}$ in the medium changes the distribution of the receptor from preferentially cell body/dendritic to axonal also for sympathetic neurons.

Using the Campenot chambers we next analyzed whether physiologically active Fe-Tf also transcytosed. ${ }^{125} \mathrm{I}$-Tf was added to the central chamber for $1 \mathrm{hr}$ at $37^{\circ} \mathrm{C}$. After they were washed, the axons in the lateral chamber were incubated for $2 \mathrm{hr}$ in culture medium without $\mathrm{Tf}$ and with nitrilotriacetic acid, a chelating agent that prevents $\mathrm{Tf}$ re-endocytosis after release at the cell surface, and radioactivity was measured in both the central and lateral chambers. Recovery of radioactive $\mathrm{Tf}$ in the central chamber reflects recycling, whereas in the lateral chambers it would reflect transcytosis. Figure $6 B$ shows that $\mathrm{Tf}$ was transcytosed from the central (cell body/dendrites) to the lateral (axonal) chamber. Recovery in the lateral chamber was $\sim 7 \%$ of the total Tf in the central and lateral chambers. However, this is an underestimation of transcytosis, because only a small fraction of the axons of the cells are in the lateral chamber. Given the low

A

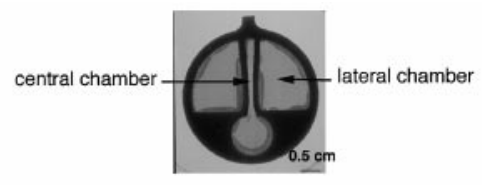

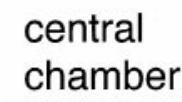

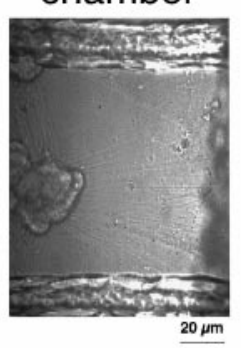

B

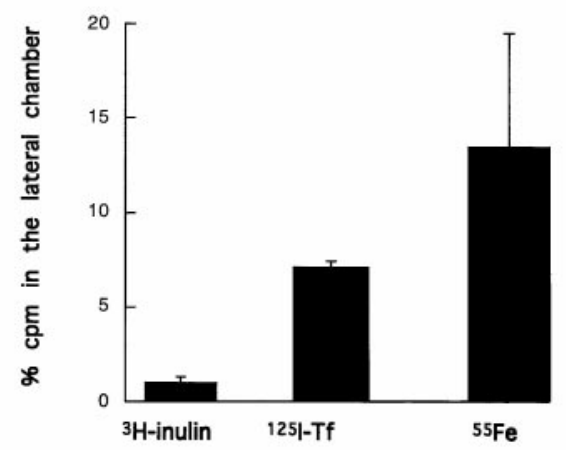

Figure 6. A, Cell body/dendrites and axons of sympathetic neurons are grown in separate environments. The top photograph shows the culture chamber at low magnification. Immediately after dissociation sympathetic neurons are plated in the central chamber. The axons from these cells will extend into the lateral chambers. At higher magnification the presence of axons and the complete lack of cell bodies in the lateral chamber is evident. Numerous axons also grow in the central chamber without ever crossing. $B$, Quantitative analysis of transcytosis of ${ }^{3} \mathrm{H}$-inulin, ${ }^{125} \mathrm{I}-\mathrm{Tf}$, and ${ }^{55} \mathrm{Fe}-\mathrm{Tf}$ in chambered sympathetic neurons. Radioactive ligands were added in the central chamber, and released radioactivity was measured 2 hr later in the lateral and central chambers. The values are the percentage of activity ( $\mathrm{cpm}$ ) recovered in the lateral chambers with respect to that of the central chambers. The data are a pool from four different experimental observations. The difference between ${ }^{125} \mathrm{I}-\mathrm{Tf} /{ }^{55} \mathrm{Fe}-\mathrm{Tf}$ and inulin recovered in the lateral chambers is statistically significant (more than sevenfold). The difference between ${ }^{125} \mathrm{I}$-Tf and ${ }^{55} \mathrm{Fe}-\mathrm{Tf}$ is not significant.

abundance of $\mathrm{TfR}$ in axons in the absence of exogenous $\mathrm{Tf}$, it is unlikely that the $\mathrm{Tf}$ released into the lateral milieu comes from $\mathrm{Tf}$ that is internalized in axons in the central chamber and anterogradely transported.

To rule out that the radioactivity in the lateral chambers was caused by leakage of medium from the central chamber, ${ }^{3} \mathrm{H}$-inulin was added to the central chambers of the same cultures, and the radioactivity was measured. Inulin was not found in significant amounts in the lateral chambers. The values for ${ }^{125} \mathrm{I}-\mathrm{Tf}$ and ${ }^{3} \mathrm{H}$-inulin are shown in Table 1.

To determine whether Tf transcytosed bound to iron, we analyzed the routing of ${ }^{55} \mathrm{Fe}-\mathrm{Tf} .{ }^{55} \mathrm{Fe}-\mathrm{Tf}$ was added to the central chamber of cultured sympathetic neurons, and its appearance was measured in the lateral chamber. Figure $5 B$ and Table 1 show that ${ }^{55} \mathrm{Fe}$ appeared in the lateral chamber at $2 \mathrm{hr}$ of chase. This result suggests that $\mathrm{Tf}$ and iron transcytose together. Although not 
Table 1. Transport of ${ }^{125} \mathrm{I}$ transferrin and ${ }^{55} \mathrm{Fe}$-transferrin from the central to the lateral compartments in "chambered" sympathetic neurons

\begin{tabular}{|c|c|c|c|}
\hline & $\begin{array}{l}\text { Central } \\
\text { chamber }\end{array}$ & $\begin{array}{l}\text { Lateral } \\
\text { chamber }\end{array}$ & $\begin{array}{l}\text { Percent in } \\
\text { the lateral } \\
\text { chamber }\end{array}$ \\
\hline \multicolumn{4}{|l|}{ Experiment 1} \\
\hline${ }^{3} \mathrm{H}$-inuline $2 \mathrm{hr}$ incubation & $92456 \mathrm{dpm}$ & $576 \mathrm{dpm}$ & 0.62 \\
\hline${ }^{125}$-I-TF 2 hr chase & $35655 \mathrm{cpm}$ & $2553 \mathrm{cpm}$ & 6.7 \\
\hline${ }^{55} \mathrm{Fe}-\mathrm{Tf} 2 \mathrm{hr}$ chase & $11400 \mathrm{dpm}$ & $864 \mathrm{dpm}$ & 7.0 \\
\hline \multicolumn{4}{|l|}{ Experiment 2} \\
\hline${ }^{3} \mathrm{H}$-inuline $2 \mathrm{hr}$ incubation & $84964 \mathrm{dpm}$ & $1120 \mathrm{dpm}$ & 1.3 \\
\hline${ }^{125} \mathrm{I}$-Tf $2 \mathrm{hr}$ chase & $42889 \mathrm{cpm}$ & $3497 \mathrm{cpm}$ & 7.5 \\
\hline${ }^{55} \mathrm{Fe}-\mathrm{Tf} 2 \mathrm{hr}$ chase & $13672 \mathrm{dpm}$ & $3408 \mathrm{dpm}$ & 20.0 \\
\hline
\end{tabular}

significant, the proportion of ${ }^{55} \mathrm{Fe}$ radioactivity recovered in the axonal milieu is higher than that of Tf. This could indicate that the proportion of Fe-bound $\mathrm{Tf}$ in the axon (transcytosing $\mathrm{Tf}$ ) is higher than that in the recycling pathway.

Transcytosis is influenced by the addition of excitatory and inhibitory neurotransmitters

In the previous sections we characterized the intracellular trafficking of Tf and TfR and showed data suggesting that transcytosis of the TfR is modulated by Tf. We next asked whether synaptic activity would also affect TfR trafficking. Synaptic activity changes ion fluxes on the postsynaptic cell by activation of neurotransmitter (NT)-receptors. Activation of the intracellular signaling cascades leads to changes in gene expression and phenotype modifications (Ginty et al., 1992). Although the effect of membrane depolarization in synaptic vesicle recycling is well characterized, it is not known whether changes in membrane potential also affect the intracellular trafficking of membrane receptors and ligands present on the dendritic membrane and dendritic milieu. This could have an important role in the plastic changes accompanying increased synaptic activity. To examine this question we added low concentrations of GABA $(10 \mu \mathrm{M})$ or glutamate $(5 \mu \mathrm{M})$ to hippocampal neurons and analyzed and quantitated the intracellular distribution of TfR (Fig. 7). As shown earlier, in cells starved from exogenous $\mathrm{Tf}$, the percentage of $\mathrm{TfR}$ in axons is $13.7 \%$. Addition of glutamate to the medium during the starvation period ( $2 \mathrm{hr}$ ) increases this to $24.1 \%$. This difference is statistically significant $(p<0.001)$. A similar effect was found on addition of NMDA to the starvation medium (not shown). However, addition of glutamate to cells grown in the presence of exogenous $\mathrm{Tf}$ produced a nonsignificant change in axonal TfR $(p>0.3)$, suggesting that transcytosis is a saturable phenomenon and could be triggered either by increasing the concentration of ligand in the medium or by increasing membrane excitability under basal levels of ligands (Fig. 6), but the effects are not additive. Contrary to the effect of the excitatory agonists, activation of inhibitory receptors by GABA decreases axonal $\mathrm{TfR}$. In the constant presence of Tf, axonal labeling accounts for $29.4 \%$; this is decreased to $17.1 \%$ in the presence of GABA $(p<$ $0.001)$. Addition of GABA to starved cells did not produce a further significant decrease in the amount of axonal $\operatorname{Tf}(p>0.1)$. Altogether these results show that there are two levels of transcytosis: a basal level, independent of membrane excitability and exogenous concentration of ligand, and a potentiated level, triggered by increasing electrical activity or extracellular ligand.

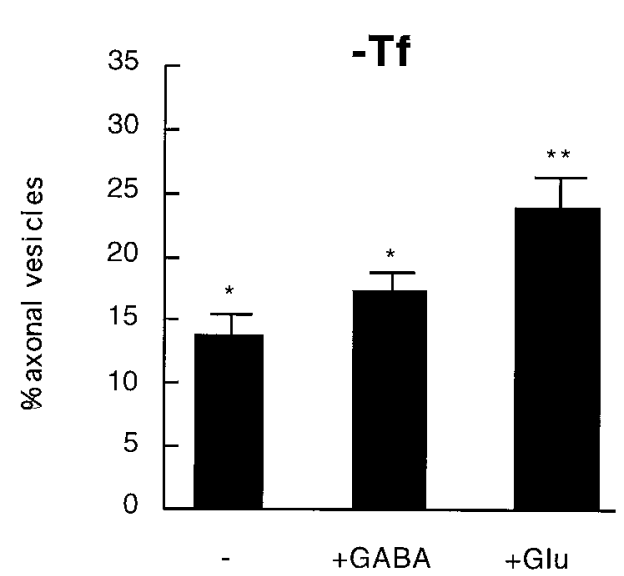

(20) (10)

(16)

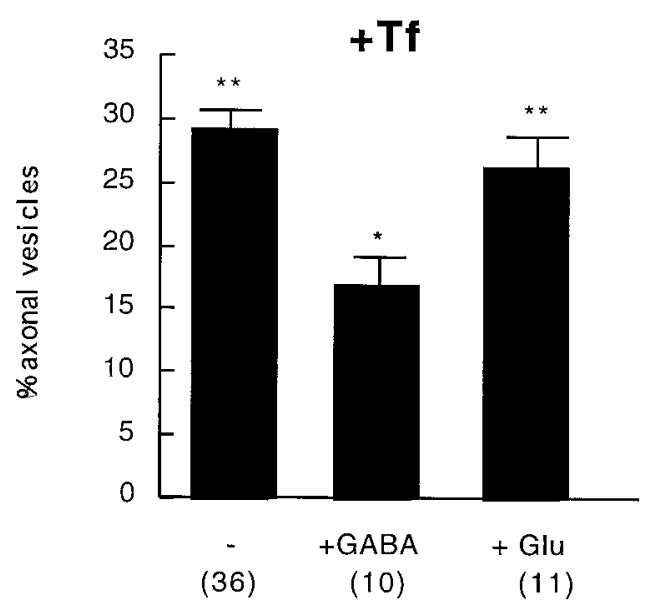

Figure 7. Histogram showing the effect of glutamate and GABA addition on the intracellular distribution of TfR. In Tf-starved cells $(-T f)$ glutamate addition induces a clear increase in the percentage of axonal TfR-positive structures $(p<0.001)(* *)$, whereas GABA addition does not significantly change the number of axonal labeled organelles. In cells grown in the constant presence of $\operatorname{Tf}(+T f)$ a $2 \mathrm{hr}$ incubation with GABA decreases the percentage of axonal TfR $(p<0.001)(*)$. Glutamate addition does not produce a further increase $(* *)$.

\section{DISCUSSION}

Our understanding of transcytosis comes largely from studies in polarized epithelial cells expressing pIgR (Mostov and Cardone, 1995). The first step in the transcytotic movement of immunoglobulins is the binding to specific high-affinity receptors on the plasma membrane followed by internalization in clathrin-coated vesicles that pinch off from the membrane and fuse with underlying early endosomes. Some of the ligand thus internalized remains associated with the receptor, possibly in an endocytic subcompartment of higher $\mathrm{pH}$ than the classic endosome, is packaged into specific carrier vesicles, and is transported to the opposite plasma membrane where release of the ligand occurs. In this work we provide evidence that in polarized hippocampal and sympathetic neurons Tf and its receptor follow a similar "classic" transcytotic pathway from the dendrites to the axons. First, exogenous Tf added to Tf-starved cells is taken up from the dendritic surface where the receptor is located (Figs. 1, 3). Second, the exogenous Tf fills submembranous early endosomes (Fig. 
4). Third, the Tf internalized in the dendrites moves to the axon in vesicular organelles (Fig. 2). Fourth, Fe-Tf internalized in the cell body/dendrite region reaches the axonal plasma membrane and is released to the axonal milieu as Fe-Tf (Fig. 5), showing efficient release of physiologically active ligand. Finally, the intracellular trafficking of Tf/TfR is increased by activation of glutamate (excitatory) receptors and decreased by activation of GABAergic (inhibitory) receptors (Fig. 6)

Our biochemical approach with the Campenot chambers reveals that $7 \%$ of Tf transcytoses. This number may be an underestimation, because the number of axons crossing the barrier into the cell body/dendrite-free chamber is far less than the number of cell bodies in the central chamber. Accurate quantitation of transcytosis would require a system in which endocytosis and recycling were measured only in those cell bodies that extend axons in the lateral chambers. No such system is available yet.

We observed that transcytosis of the TfR is stimulated by the presence of ligand; in its absence most receptors are dendritic. This is consistent with previous results using starved cells (Parton et al., 1992). The dendritic distribution of $\mathrm{TfR}$ found in nonstarved hippocampal neurons (Cameron et al., 1991) might be explained by the presence of apo-Tf, and not holo-Tf, in the culture medium. Although the effect of Tf in the trafficking of the receptor is not very well documented, differences have been measured in the kinetics of endocytosis and recycling of the TfR in the absence and presence of Tf (Girones and Davis, 1989; Sainte-Marie et al., 1991). These authors have shown that Tf accelerates both endocytosis and, to a larger extent, recycling of the TfR, resulting in the highest proportion of $\mathrm{TfR}$ at the cell surface in the presence of Tf. Moreover, we could assume that the increase in transcytosis of $\mathrm{TfR}$ in the presence of ligand is controlled by a mechanism similar to that resulting in increased transcytosis of the pIgR in the presence of dimeric immunoglobulin A (dIgA) (for review, see Mostov and Cardone, 1995).

We also show that iron is transcytosed, suggesting that the axonally transported $\mathrm{Tf}$ is still bound to iron and therefore able to bind to receptors in the target cells on release. This shows that transcytosis of Tf may play a physiological role and that iron accumulation in certain brain regions may arise by this mechanism. Other trophic factors such as FGF and NGF could also act via transcytosis (Ferguson et al., 1990; von Bartheld et al., 1996).

The fact that iron is transcytosed raises the question of the transcytotic pathway in neurons. Under the low $\mathrm{pH}$ of endocytic compartments, iron dissociates from Tf (Dautry-Varsat et al., 1983). Therefore the axonally transported iron may be bound to $\mathrm{Tf}$ in a nonacidic compartment. Whether separate compartments exist in neurons for the sorting of Tf destined for transcytosis and recycling is not known. In epithelial cells, transcytotic molecules endocytosed from the basolateral surface join an apical recycling compartment in which sorting between basolaterally and apically targeted molecules occurs. In epithelial cells, Tf accumulates in this apical recycling compartment after long internalization times. Whether this is the case in neurons and whether $\mathrm{Tf}$ destined for transcytosis accumulates in an axonal "recycling" compartment is not known. In the case of differentiated neurons, we did not detect any "large" Tf-containing compartment in axons (Fig. 1), suggesting that a similar compartment does not exist. However, it is possible that the recycling compartment is present in the cell body. Another interesting and unresolved matter is the mechanism of iron/Tf release on the axonal surface. One can envision that ligand and receptor exposed to the extracellular millieu dissociate because of the low concentration of ligand in this environment, simply following the rules of concentration kinetics. This could explain the release of ligand in the lateral chambers of cultured sympathetic neurons. In situ, ligand would dissociate from the receptor in regions where adjacent cells express a large number of unoccupied receptors.

Our work shows that dendroaxonal transcytosis is used for Tf. This simple discovery opens numerous questions for both cell biology and neurobiology. From a cell biology perspective, it would be of interest to know whether the signals for transcytosis in the $\mathrm{Tf}$ receptor are the same as those for other transcytotic molecules (i.e., pIgR), where transcytosing and recycling $\mathrm{Tfs}$ are sorted, and what are the mechanisms of transport. For neurobiology, the challenge ahead is the physiological role of transcytosis both during neuronal development and in the mature brain. Our results on the increase of $\mathrm{Tf}$ transcytosis after activation of glutamate (excitatory) but not GABAergic (inhibitory) synapses would suggest that the changes that take place after increased synaptic activity might also be mediated by changes in uptake and trafficking of trophic factors. It is well known that anterograde effects in the nervous system, those from neurons to their target organs, are mediated by activation of neurotransmitter receptors on the postsynaptic cell (Comb et al., 1987; Ginty et al., 1992). The activation of neurotransmitter receptors leads to the stimulation of second messenger systems that transfer the signals to the nucleus where expression of specific genes is regulated. Our data show that NT-receptor activation also induces changes in uptaketrafficking of trophic factors normally present in the extracellular milieu. One possibility is that the electrical activity-induced increase in uptake-transcytosis of extracellular ligands in the postsynaptic cell plays a role in the appearance of phenotypic changes normally observed under such conditions. Alternatively, the increase in intracellular trafficking does not have a direct effect on the postsynaptic cell were NT-receptor activation took place but on distant targets. Whether the increase observed in transcytosis after glutamate/NMDA activation is attributable to an increase in endocytosis or exclusively in transcytosis is not yet clear. Because activation of NMDA receptors by glutamate stimulates protein tyrosine phosphorylation (Bading and Greenberg, 1991) and phosphorylation increases TfR transcytosis in epithelia (Cardone et al., 1994), the increase in axonal TfR could be attributable to higher transcytosis. The data on synaptic activity and transcytosis may have an important physiological connotation; trophic factors present in the external milieu can be more or less efficiently used by the postsynaptic cell or by cells at distant places depending on the type of trans-synaptic activity. Our work paves the way for the study of the functional implications of transcytosis during neuronal development and for the long-term adaptive changes in the mature brain, events in which transsynaptic regulation of gene expression is involved.

\section{REFERENCES}

Bading H, Greenberg ME (1991) Stimulation of protein tyrosine phosphorylation by NMDA receptor activation. Science 253:912-914.

Beard JL, Connor JR, Jones BC (1993) Iron in the brain. Nutr Rev 51:157-170.

Bottenstein JE, Sato GH (1979) Growth of a rat neuroblastoma cell line in serum-free supplemented medium. Proc Natl Acad Sci USA 76:514-517.

Brändli AW, Adamson ED, Simons K (1991) Transcytosis of epidermal growth factor. J Biol Chem 266:8560-8566.

Caceres A, Banker G, Steward O, Binder L, Payne M (1984) MAP2 is localized to the dendrites of hippocampal neurons which develop in culture. Dev Brain Res 13:314-318.

Cameron PL, Südhof TC, Jahn R, de Camilli P (1991) Colocalization of 
synaptophysin with transferrin receptors: implication for receptor biogenesis. J Cell Biol 115:151-164.

Campenot RB (1992) Compartmented culture analysis of nerve growth. In: Cell-cell interactions (Stevenson BR, Gallin WJ, Paul DL, eds), pp 275-298. Oxford: IRL.

Cardone MH, Smith BH, Song W, Mochly-Rosen D, Mostov KE (1994) Phorbol myristate acetate-mediated stimulation of transcytosis and apical recycling in MDCK cells. J Cell Biol 124:717-727.

Cerneus DP, Strous GJ, van der Ende A (1993) Bidirectional transcytosis determines the steady state distribution of the transferrin receptor at the opposite plasma membrane domains of BeWo cells. J Cell Biol 122:1223-1230.

Comb M, Hyman SE, Goodman HM (1987) Mechanisms of transsynaptic regulation of gene expression. Trends Neurosci 10:473-478.

Craig AM, Banker G (1994) Neuronal polarity. Annu Rev Neurosci 17:267-310.

Dautry-Varsat A, Ciechanover A, Lodish HF (1983) pH and the recycling of transferrin during receptor-mediated endocytosis. Proc Natl Acad Sci USA 80:2258-2262.

de Hoop M, von Poser C, Lange CII, Hunziker W, Dotti CG (1995) Intracellular routing of wild-type and mutated polymeric immunoglobulin receptor in hippocampal neurons in culture. $\mathrm{J}$ Cell Biol 130:1447-1459.

De Strooper B, Simons M, Multhaup G, Van Leuven F, Beyreuther K, Dotti CG (1995) Production of intracellular amyloid containing fragments in hippocampal neurons in culture expressing mutants of APP causing Alzheimers disease and protection against amyloidogenesis by subtle amino acid substitutions in the rodent sequence. EMBO J 14:4932-4938.

Dumas M, Schwab ME, Baumann R, Thoenen H (1979) Retrograde transport of tetanus toxin through a chain of two neurons. Brain Res 165:354-357.

Evinger C, Erichsen JT (1986) Transsynaptic retrograde transport of fragment $\mathrm{C}$ of tetanus toxin demonstrated by immunohistochemical localization. Brain Res 380:383-388.

Faucheux BA, Nillesse N, Damier P, Spick G, Mouatt-Prigent A, Pierce A, Laveugle B, Kubis N, Hauw J-J, Agid Y, Hirsch EC (1995) Expression of lactoferrin receptors is increased in the mesencephalon of patients with parkinson disease. Proc Natl Acad Sci USA 92:9603-9607.

Ferguson IA, Schweister JB, Johnston EM (1990) Basic fibroblast growth factor: receptor-mediated internalization, metabolism, and anterograde axonal transport in retinal ganglion cells. J Neurosci 10:2176-2189.

Fraker PJ, Speck Jr JC (1978) Protein and cell membrane iodinations with a sparingly soluble chloroamide, 1,3,4,6-tetrachloro-3a, 6adiphenylglycoluril. Biochem Biophys Res Commun 80:849-857.

Friden PM, Walus LR, Musso GF, Taylor MA, Malfroy B, Starzyk RM (1991) Anti-transferrin receptors antibody-drug conjugates cross the blood-brain barrier. Proc Natl Acad Sci USA 88:4771-4775.

Ghinea N, Vu Hai MT, Groyer-Picard M-T, Milgron E (1994) How protein hormones reach their target cells. Receptor mediated transcytosis of hCG through endothelial cells. J Cell Biol 125:87-97.

Ginty DD, Bading H, Greenberg ME (1992) Trans-synaptic regulation of gene expression. Curr Opin Neurobiol 2:312-316.

Girones N, Davis RJ (1989) Comparison of the kinetics of cycling of the transferrin receptor in the presence or absence of bound diferric transferrin. Biochem J 264:35-46.

Goslin K, Banker G (1991) Rat hippocampal neurons in low-density culture. In: Culturing nerve cells (Banker G, Goslin K, eds), pp 251281. Cambridge, MA: MIT.

Hashida R, Anamizu A, Kimura J, Ohkuma S, Youhida Y, Takano T (1986) Transcellular transport of lipoprotein through arterial endothelial cells in monolayer culture. Cell Struct Funct 11:31-42.

Hémar A, Subtil A, Lieb M, Morelon E, Hellio R, Dautry-Varsat A (1995) Endocytosis of interleukin 2 receptors in human $\mathrm{T}$ lymphocytes: distinct intracellular localization and fate of the receptor $\alpha, \beta$ and $\gamma$ chains. J Cell Biol 129:55-64.

Higgins D, Lein PJ, Osterhout DJ, Johnson MI (1991) Tissue culture of mammalian autonomic neurons. In: Culturing nerve cells (Banker G, Goslin K, eds), pp 177-205. Cambridge, MA: MIT.

Hill JM, Ruff MR, Weber RJ, Pert CB (1985) Transferrin receptors in rat brain: neuropeptide-like pattern and relationship to iron distribution. Proc Natl Acad Sci USA 82:4553-4557.

Hunziker W, Mellman I (1989) Expression of macrophage-lymphocyte Fc receptors in Madin-Darby canine kidney cells: polarity and transcytosis differ for isoforms with or without coated pit localization domains. J Cell Biol 109:3291-3302.
Ikonen E, Parton RG, Hunziker W, Simons K, Dotti CG (1993) Transcytosis of the polymeric immunoglobulin receptor in cultured hippocampal neurons. Curr Biol 3:635-644.

Kiffmeyer WR, Tomusk EV, Mescher AL (1991) Axonal transport and release of transferrin in nerves of regenerating amphibian limbs. Dev Biol 147:392-402.

King GI, Johnson S (1985) Receptor-mediated transport of insulin across endothelial cells. Science 227:1583-1586.

Klausner RD, Ashwell JV, Van Renswoude J, Harford JB, Bridges KR (1983) Binding of apotransferrin to K562 cells: explanation for the transferrin cycle. Proc Natl Acad Sci USA 80:2263-2266.

Kuypers HGJM, Ugolini G (1990) Viruses as transneuronal tracers. Trends Neurosci 13:71-75.

LaVail JH, Margolis TP (1987) The anterograde axonal transport of wheat germ agglutinin as a model for transcellular transport in neurons. In: Axonal transport (Smith RS, Bisby MA, eds), pp 311-326. New York: Alan Liss.

Loeffler DA, Connor JR, Juneau PL, Snyder BS, Kanaley L, DeMaggio AJ, Nguyen H, Brickman CM, LeWitt PA (1995) Transferrin and iron in normal, Alzheimer's disease, and Parkinson's disease brain regions. J Neurochem 65:710-716.

Maratos-Flier E, Kao C-YY, Verdin EM, King GL (1987) Receptormediated vectorial transcytosis of epidermal growth factor by MadinDarby canine kidney cells. J Cell Biol 105:1595-1601.

Markelonis GJ, Oh TH, Park LP, Cha CY, Sofia CA, Kim JW, Azari P (1985) Synthesis of the transferrin receptor by cultures of embryonic chicken spinal neurons. J Cell Biol 100:8-17.

Mitchison TJ (1989) Polewards microtubule flux in the mitotic spindle: evidence from photoactivation of fluorescence. J Cell Biol 109:637-652.

Morris CM, Candy JM, Keith AB, Oakley AE, Taylor GA, Pullen RG, Bloxham CA, Gocht A, Edwardson JA (1992) Brain iron homeostasis. J Inorg Biochem 47:257-265.

Mostov KE (1991) The polymeric immunoglobulin receptor. Semin Cell Biol 2:411-418.

Mostov KE, Cardone MH (1995) Regulation of protein traffic in polarized epithelial cells. BioEssays 17:129-138.

Nelson WJ (1992) Regulation of cell surface polarity from bacteria to mammals. Science 258:948-955.

Neutra MR, Wilson JM, Weltzin RA, Kraehenbuhl JP (1988) Membrane domains and macromolecular transport in intestinal epithelial cells. Am Rev Respir Dis 138:S10-6.

Olivo JC (1992) Nanometer-size metal particle analysis in microscopical biological images. In: Image processing algorithms and techniques III (Sullivan JR, Rabbani M, Dawson BM, eds), pp 558-562. San Jose, CA: SPIE).

Parton RG, Simons K, Dotti CG (1992) Axonal and dendritic endocytic pathways in cultured neurons. J Cell Biol 119:123-137.

Pickard GE, Silverman A-J (1981) Direct retinal projections to the hypothalamus, piriform cortex, and accessory optic nuclei in the golden hamster as demonstrated by a sensitive anterograde horseradish peroxidase technique. J Comp Neurol 196:155-172.

Press WH, Teukolsky SA, Vetterling WT, Flannery BP (1992) Numerical recipes in $\mathrm{C}$. The art of scientific computing, Ed 2. Cambridge, UK: Cambridge UP.

Rodriguez-Boulan E, Powell SK (1992) Polarity of epithelial and neuronal cells. Annu Rev Cell Biol 8:395-427.

Sainte-Marie J, Vidal M, Bette-Bobillo P, Philippot JR, Bienvenüe A (1991) The influence of transferrin binding to $\mathrm{L}_{2} \mathrm{C}$ guinea pig leukemic lymphocytes on the endocytosis cycle kinetics of its receptor. Eur J Biochem 201:295-302.

Siminoski K, Gonella P, Bernake J, Owen L, Neutra M, Murphy RA (1986) Uptake and transepithelial transport of nerve growth factor in suckling rat ileum. J Cell Biol 103:1979-1990.

Soda R, Tavassoli M (1984) Transendothelial transport (transcytosis) of iron-transferrin complex in the blood marrow. J Ultrastruct Res 88:18-29.

Sooranna SR, Contractor SF (1991) Vectorial transcytosis of immunoglobulin $\mathrm{G}$ by human term trophoblast cells in culture. Exp Cell Res 192:41-45.

Sterverding D, Stierhof Y-D, Fuchs H, Tauber R, Overath P (1995) Transferrin-binding protein complex is the receptor for transferrin uptake in Trypanosoma brucei. J Cell Biol 131:1173-1182.

von Bartheld CS, Byers MR, Williams R, Bothwell M (1996) Anterograde transport of neurotrophins and axodendritic transfer in the developing visual system. Nature 379:830-833. 